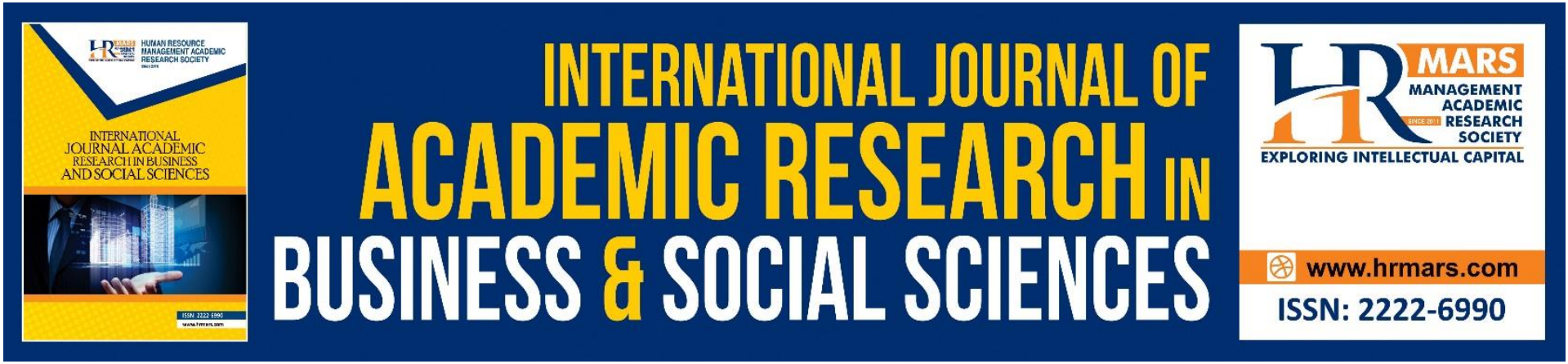

\title{
A Review on Systematic Guided Reading Strategies and Its Implication on Reading Comprehension
}

Nik Intan Baizura Ramsa, Rafizah Mohd Rawian

To Link this Article: http://dx.doi.org/10.6007/IJARBSS/v11-i6/10112

DOI:10.6007/IJARBSS/v11-i6/10112

Received: 05 April 2021, Revised: 07 May 2021, Accepted: 26 May 2021

Published Online: 05 June 2021

In-Text Citation: (Ramsa \& Rawian, 2021)

To Cite this Article: Ramsa, N. I. B., \& Rawian, R. M. (2021). A Review on Systematic Guided Reading Strategies and Its Implication on Reading Comprehension. International Journal of Academic Research in Business and Social Sciences, 11(6), 203-215.

Copyright: (c) 2021 The Author(s)

Published by Human Resource Management Academic Research Society (www.hrmars.com)

This article is published under the Creative Commons Attribution (CC BY 4.0) license. Anyone may reproduce, distribute, translate and create derivative works of this article (for both commercial and non-commercial purposes), subject to full attribution to the original publication and authors. The full terms of this license may be seen at: http://creativecommons.org/licences/by/4.0/legalcode

Vol. 11, No. 6, 2021, Pg. 203 - 215

http://hrmars.com/index.php/pages/detail/IJARBSS

JOURNAL HOMEPAGE

Full Terms \& Conditions of access and use can be found at

http://hrmars.com/index.php/pages/detail/publication-ethics 


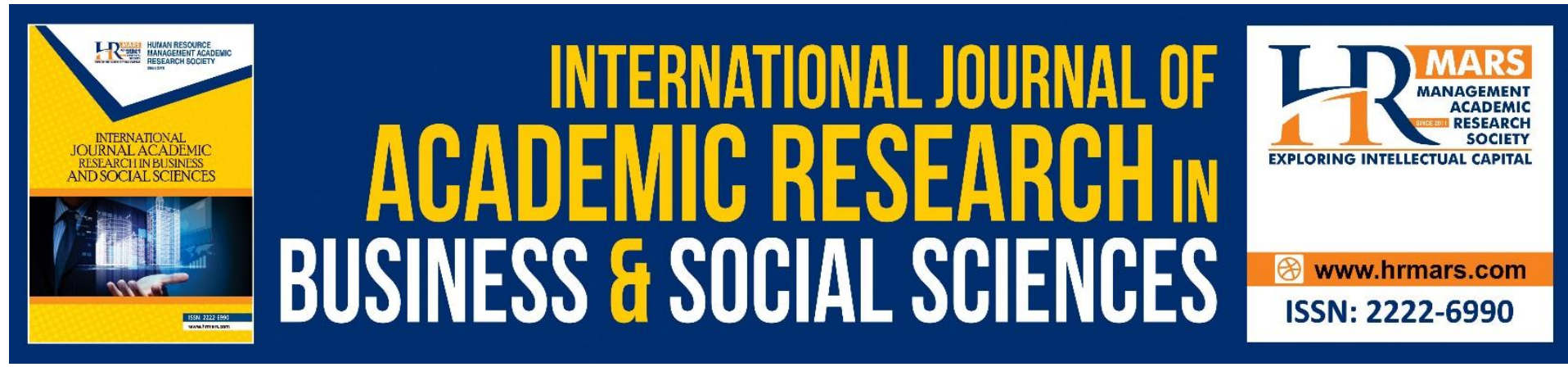

\title{
A Review on Systematic Guided Reading Strategies and Its Implication on Reading Comprehension
}

\author{
Nik Intan Baizura Ramsa, Rafizah Mohd Rawian \\ School of Languages, Civilization and Philosophy, Universiti Utara Malaysia \\ Email:ms_ramsa@yahoo.co.uk,rafizah@uum.edu.my
}

\begin{abstract}
Guided reading strategies is a vital method in teaching and learning process. Guided reading facilitates teachers to deliver very operational support for students' who have literacy issues especially for reading comprehension. The method is also applicable in conjunction with other reading activities such as reading aloud, independent reading and shared reading. Teachers play an important role in guiding their students with systematic reading strategies as scaffolding measure in literacy learning. The strategies will actively improve students' understanding and help to develop their comprehension skills. Teachers need to be attentive and value the systematic, guided reading strategies that act as the sustenance for their students' reading comprehension. It is essential to discover and recognise the feasible reading strategies that emphasise such effort. This paper attempts to figure out this with value to guided reading strategies. It concerns with pre-reading strategies, during reading strategies and post-reading strategies to enhance reading comprehension.
\end{abstract}

Keywords: Reading Strategies, Reading Comprehension, Scaffolding Measure, Schemata, Systematic Reading Strategies

\section{Introduction}

Reading is probably the most widely and exhaustively studied by language researchers compared to the other three language skills (Pardede, 2017). The results of the previous studies conducted on reading strategies reported that, directed and systematic instruction of reading strategies will improve reading comprehension (Richardson, 2010). Reading is a cooperative process in which readers dynamically involve with the written texts, constructing their own understanding towards the author's intended message. Reading comprehension, on the other hand, is vital to ensure students' literacy in countless subject fields as it involves with many different mental activities that should be done automatically and simultaneously to get the meaning expressed in a text (Maroua, 2020). It is essential for students to understand as well as hold the information they are reading. The meaning they formulate is the central of the reading process (Pressley, 1998, Braunger \& Lewis, 1998, as cited in Biddulph, 2002). However, when a teacher notices one or more of their students are having literacy issues with comprehension, it is critical to set and execute systematic strategies to aid and minimise these stumbling blocks. According to Richardson (2010), guided reading 
strategies are frequently practiced aiding struggling students with reading comprehension. Through the application of guided reading strategies, students will become more conscious of how text works (Kasten, Kristo, \& McClure, 2005). In guided reading process, teachers need to demonstrate the "tricks of the trade", later arrange for persistent support to facilitate them become self-reliant readers and writers (Kasten, Kristo, \& McClure, 2005). According to Richardson (2010), effective modelling and implementation of systematic strategy instruction is paramount practice to aid struggling students with reading comprehension to see how the process works. Therefore, guided reading strategies act as an effective tool to improve students' reading comprehension. Pre-reading strategies, during reading strategies and postreading strategies are collectively merged in the process to accelerate learning and improve literacy.

\section{The Importance of Reading Comprehension Strategies}

Reading comprehension strategy is the most important skill to master especially for second language or foreign language students. Pardede (2017) claimed that students can normally accomplish at a greater level in reading compared to any other language skills. They can entirely apprehend the written texts even they are unable to converse orally or in written discourse with precise correspondent. This situation will certainly boost their motivation to learn. Secondly, reading demands very minimum requisites. Compared to speaking which requires prospects to interact with the second party or from writing that dictates a lot of supervision and time consuming to practice, reading only wishes for a text and motivation. Thirdly, reading is a service skill (Pardede, 2017). Students will be capable of being an effective learner by reading when they can master to read effectively.

Grabe (2009) as cited in Hamidreza and Hashemi (2016) stressed the significance of reading comprehension strategies clearly: "Acquisition of better reading strategies is apparently needed to crack the illusion of comprehension in readers who are settling for low standards of comprehension; They need to acquire and implement strategies to facilitate deeper levels of comprehension" (p. 449). Hence, aiding students' reading comprehension through systematic guided reading strategies has been a central focus for teachers. It has often been argued in reading literature that due to the complex and complicated factors involved in reading comprehension in general and in EFL reading i.e., linguistic, cognitive, and socio-cultural variables, designing an effective reading instructional strategy is not an easy task (Hudson, 2007, as cited in Abdelhalim, 2017).

Considering the vitality of reading comprehension for students, we can perceive that developing their reading ability is at utmost condition. Therefore, teachers should plan a strategy that can improve the instructional to carry out the feasible strategies and techniques. Various systematic guided reading strategies should be implemented in class to identify which strategy works well with students, if not they are still at a disadvantage.

\section{Literacy and Reading Strategies}

People involve in literacy events for various reasons. Literacy is not only covering oral or written language only but it is all incorporated (Richardson, 2010). When learning is growing to be more authentic and self-centred, then literacy is seen as a multidimensional activity. We practice this literacy activities daily through all-four language skills activity as well as during connections using technology or gadgets. To comprehend literacy acquisitions, initially, one must be able to recognise the developmental aspects of that specific language and other elements that affect this development such as sociocultural differences and 
historical settings. The development of the language must be objectively focused from various cultural viewpoints in order to understand how a person starts to learn and acquire literacy. Hence, a synthesis of cultural and linguistic variants must be precisely explored and analysed to fully apprehend the connexion of literacy acquisition on language development.

Every student caters the reading text differently based on their background schemata or past experience (Larson \& Marsh, 2005). Due to students' different social, cultural, and historical contexts of interaction, there is a need for feasible and effective use of reading strategies to encourage a strong fundamental of literacy skills that adjustable on each student. There are no strategies that fits-all, but still applicable with certain modifications to suit the needs and level. In this situation, teacher must be more flexible and decide the strategies that will most benefit the students. Freebody and Luke (1990) proposed four reader roles that maintain characters established in systematic guided reading strategies which comprises the main elements of reading while supplying information for teachers whether or not still a necessity for students to receive additional training as well as areas that need help or to be focused on. Freebody and Luke further explained that readers' four roles are: code breaker, text participant, text user and, text analyst. These four roles are paralleled to prereading, during-reading and post-reading strategies that boost reading comprehension while aiding teacher to cater students' individual needs.

Understanding that each student has different way of learning style and acquisition, and teachers can train numerous guided reading strategies during the reading experience, this situation will boost students' confidence and polish their reading abilities. Therefore, it is crucial for teachers to consider students' multiple learning styles. Teacher should consider multiple systematic guided reading strategies when students are struggling with reading comprehension. According to McNamara (2004), incorporating background knowledge of comprehension strategies will assist young readers to develop their comprehension skills. It has been verified that students who acquire reading strategy knowledge at an earlier stage, are more advance to understand the text (McNamara, O’Reilly, Best \& Ozuru, 2006).

\section{The Definition of Comprehension}

Comprehension is a central part of learning which has multi-dimensional stages within multi-layers of understanding. It is essential to a student to successfully engage with the written text. It would be very inspiring if the students could easily comprehend and utilised their comprehension skills and use them aptly in their reading. According to Sargent et.al (2009), comprehension can be defined as "the understanding of text" and it frequently requires "explanations, interpretations, applications, perspectives, empathising, and selfmonitoring", (p.362). When a reader can still read the words but he or she are unable to decipher the meaning from the text, that is not consider as reading (Literacy Information and Communication System online, 2010). Hence, if the general idea of reading is to understand the writers' intended meaning, and comprehension is crucial to generate the meaning, so readers must be trained how to apply reading strategies in order to be a productive reader.

\section{Schema Theory and comprehension}

Shen (2008) mentioned that schema theory contributes to our understanding of reading as an interactive process where incoming data are processed in the brain by means of interaction with formerly existing knowledge called background knowledge or schemata, and not just as a passive activity where information is placed into the reader's mind. Schema theory is very much applied in comprehension process because students' background 
schemata will be activated to decipher a text. The ability to recall the schemata plays an important role as the students will relate their past experiences to new experiences that might include the information of "objects, situations, and events as well as knowledge of procedures for retrieving, organising and processing information" (Kucer, 1987, p.31).

McLaughlin and Overturf (2013) claimed that in reading, comprehension is imitated in schema-based learning development, which promotes the idea that learning takes place when new knowledge is integrated with previously collected information. In other words, the more a reader knows about a given issue, the easier it is for them to make associations between what they know and what they are learning. Closely connected with schema theory, the notion of scaffolding measure through teacher-guided strategies became central in this paper. The core idea behind scaffolding measure reading strategy is basically that the learner can and will only have access to knowledge that is within what Vygotsky referred to as the Zone of Proximal Development (ZPD). According to Attarzadeh, research has suggested that scaffolding is a "mediating strategy which must be both levelled for the learner's apparent ZPD and helpful" in overcoming the procedural problems already displayed by the learner along the course of the educational experience $(2011$, p. 5). Therefore, for successful reading comprehension to take place, it is necessary to set up the pedagogical conditions that: a) permit the reader to relate newly incoming knowledge to existing background schemata he already obtained and b) guarantee that all incoming data are within the learners' ZPD by means of scaffolded pre- reading activities that, altogether, help the students connect the gaps between the new and the soon-to-be learned information.

It became essential to complement the principles of schema theory with those of scaffolding measure for reading comprehension into a procedure of pre-, during-, and postreading activities. According to Alyousef (2005), in the pre-reading stage, schema activation takes place by means of assisting the students become alert of the background schemata they already have built in. In the during-reading stage, transaction with the reading text follows by means of reading strategies such as building mind maps, summarizing, getting the gist, scanning, skimming, and others. Alyousef also stated that during-reading activities have proven effective because they enable the reader to "tackle the text by developing their linguistic and schematic knowledge" (2005, p. 150). He further added that recent research has emphasized the essential of specific during-reading activities because they permit for the conjunction of top-down and bottom-up processing activities in the reading comprehension event. The final stage is the post-reading stage. In this stage, teachers should take the time to reflect upon the reading experience and to wrap up the lesson through classroom activities such as matching exercises, close exercises, and/or "cut-up sentences and comprehension questions" (Alyousef, 2005, p. 150). The notion behind this final stage is to ensure that actual reading comprehension has occurred and that students have the opportunity to reflect upon their learning process.

\section{Comprehension Instruction}

The needs of the students should be the centre of the focus for literacy instead of on what is popularly being taught in other group of readers. Cassidy and Cassidy (2004) mentioned that currently teachers are consistently trying to discover the most effective and feasible comprehension strategies and apply them to their students. However, it is more vital for the teachers to tailor-made their instructional to meet their students' needs. Dewitz, Jones, and Leahy (2009) claimed that comprehension instruction must always begin with direct, clear instructional focus and how each strategy can be applied throughout the reading 
process. They further added that clear comprehension instruction will build their awareness of the cognitive thought processes throughout the process. Six major instructional approaches have been identified such as workbook practice, customised schema-based learning, situated practice, conceptual learning, transactional learning, and core reading program (Block et al., 2009). The Education Endowment Foundation (2017: 12) as cited in Dunkling (2019) anticipated that effective reading comprehension comprises of the following skills: making prediction, summarizing, making inference, and activating background schemata (from previous reading in the text and applying own knowledge of real-life context).

\section{Procedures for Successful Instructional of Systematic Guided Reading Strategies}

The procedures are arranged accordingly in three prominent sections which are equivalent with the three sequential reading stages: pre-reading, during-reading and postreading (Bulut, 2017). Pre-reading strategies involves preparing instructional reading plan, extracting the topic from the first sentence of the paragraph, composing predictions from the main heading, sub-headings, visual information, activating background schemata, setting the focus, and deciding the reading speed (Mihara, 2011; Lau, 2006). However, during-reading strategies include building connections between paragraphs, underlining and taking notes on important points, guessing meaning from context for unfamiliar vocabulary, re-reading difficult parts to understand, utilizing graphic information, re-analysing if there is disparity of information is found, and forming connections between background schemata and new schemata gathered (Tankersly, 2003; Mokhtari \& Reichard, 2002). The post-reading strategies encompass several other strategies such as summarizing the reading text, inspecting previous predictions made, assessing the main ideas of the reading text critically, making notes for future reference, completing the questions (if any) and expressing the main ideas of the text (Yang, 2006).

\section{Pre-reading Tips}

Before the actual reading process is done, some important points should be taken into consideration to ensure the reading process is more meaningful.

\section{Familiarity}

The reading text should be carefully chosen to make sure that the texts comprise of familiar words and grammatical structures to the readers. However, teacher can initiate new key vocabulary in pre-reading activities that give special attention on language awareness through discovery of synonyms, antonyms, derivatives, or related words from the reading content (Pardede, 2017).

\section{Interesting topics or issues}

It is very much recommended for teachers to ensure that the topics of texts are within students' level of range-age, interests, gender, cultural background, and historical setting. Necessary background information should be provided if they are introduced to new topic or issues to accelerate comprehension.

\section{Stage 1-Pre-reading}

Pre-reading activities must be carefully planned to activate students' background schemata, develop new schemata and able to provide enough information to the teacher about what is the outcome of the planned activities. Chen and Graves (1995) defined pre- 
reading activities as a device that connecting the gap between the writers' intended message in the written text and the reader's schemata. Countless activities and materials are able to assist teacher to establish key vocabulary and strengthen the concept that stimulate both formal and subject schemata. Formal schemata will be initiated through employment of devices such as progress organisers to draw awareness to the structure of that particular written text. However, the subject schemata will be triggered through various pre-reading activities to assist readers to brainstorm and forecast how that information matches with their previous knowledge.

Prediction is the most significant pre-reading activities proposed by schematic theorists. "Prediction is crucial because the brain is always anticipating and predicting as it seeks order and significance in sensory inputs", (Goodman, 1988, p.16). According to Smith (1994), prediction refers to questions asked by the reader while comprehension is getting the answers. This prediction will train a reader to be an effective reader when the reading materials that contain subject matters that are accustomed to them.

Previewing is another pre-reading activity when students scan for titles, headings, subheadings, pictures, text organisers and skim through the first few and last paragraphs which help students to get ideas about what the text is all about through activation of their formal and subject's schemata. This activity will make them getting familiar with the topic before the go for the meaning intensely in the actual reading.

Semantic mapping is other alternative of pre-reading activity that requires students to brainstorm about the reading topic to get as much information on a graphic "map". When the students are able to see the connections from the information in the map, a comprehensive summary of the concepts and vocabulary will be developed even the student do not yet read the text. Therefore, it is advisable for teachers to select texts that contain materials that are familiar and attractive to the students.

Teacher-directed pre-reading describes new key vocabulary, main ideas in the text and the type of the text itself. Teacher will directly introduce new key concepts, important keywords, relevant conceptual framework, and related information to the students. Teacher should also choose different types of text to get the students be familiar with different forms and develop their understanding of the arrangement of the materials or ideas. Later, as the students are familiar with the text, their focus will be deeper (Pardede, 2017).

Collaborative activities require teacher to stretch the information (background schemata) hold by the students and incorporate new information for better understanding of the text. This activity will expand students' vocabulary list and familiarity with different genres of text.

Reflective activities are considered as successful once the readers become more mature with the reading process when they themselves are aware of the purpose, need and goal for reading the text. This activity is time consuming and needs a lot of practice, but the result is fruitful. 


\section{Stage 2-During-reading}

During reading-stage might be the most complex process in classroom setting. The activities that can be carried out during this stage includes notetaking, reacting, making predictions, deciding important information, making evaluation as well as relating a text with one's own experience. These activities need the teacher to aid students to be dynamic readers.

Making predictions: the students should be guided to observe what is needed to predict what is going to happen next in the reading materials and be able to incorporate what has come with what is to come.

Making selections: a more proficient readers will read selectively then make decisions about what to do with the reading text.

Incorporating background schemata: the background schemata that have been activated during pre-reading stage should be recollected to accelerate understanding.

Omitting insignificant parts: a good reader will focus on important details while omitting less or unimportant pieces.

Re-reading: teachers should reassure their students to become more perceptive to the impression of reading on their understanding.

Guessing meaning from context: students should be encouraged to guess the unknown words from contextual clues instead of stressing to define every single word in the reading text.

Chunking words into their component part: the comprehension process will be more efficient when the reader is able to break the long sentences into smaller chunks; affixes, phrases

Reading in chunks: reading the text in groups of words will enhance reading speed. Accordingly, comprehension can be improved by giving special attention to groups of meaning-conveying symbols concurrently.

Pausing: a good reader will pause at certain places to engage and reflect the reading materials and sorting out the important information.

Paraphrasing: it might be essential to paraphrase and decipher reading text sub-vocally to validate what was understood.

Checking: good readers check their comprehension to evaluate their goals of reading.

\section{Stage 3- Post-reading}

Post-reading activities essentially are subjected to the goals of reading and the type of information extracted from the text (Pardede, 2017). Post-reading exercises confirm students' comprehension then lead them for a deeper analysis of the reading material. In the 
real world, the goal of reading is to see how two different minds are engaged rather than to memorize or come up with a summary of the writers' words (Barnett, 1988).

Making questions: Teacher can promote students to make questions that will trigger deeper understanding. This activity can be done whether in writing or orally.

Answering questions: Some texts are constructed with a few questions that follows towards the end of the text to ensure readers are getting the writers' writing intention.

Filling in forms and charts: this is to train students to extract the specific information from the text thus verifying their comprehension status.

Writing reading journals: this activity will not only verify students' comprehension but polish their writing skills to convey their understanding in written discourse.

Completing a text: the activity is like "close-passage" that fill the blanks with specific, related details.

Group discussion: the activity will aid students to concentrate on the specific details they did not comprehend during their reading session or did comprehend accurately. Hence, teachers should give attention to processes that directed to comprehension or miscomprehension.

Summarising: the summary can be done in spoken or written form to check students' comprehension

Listening to or read other related materials: this activity will deepen students' understanding through expansion of terminologies or vocabularies, ideas and situational context.

Role-playing: even this activity is a bit time-consuming, but it is worth as it will show how students portray their understanding through body language, words and gestures.

\section{The Benefits of Systematic Guided Reading Strategies}

\section{Provide effective support for students' literacy learning}

A teacher who applies guided reading approach will provide effective support for students' literacy process through 1) selection of appropriate texts that match students' reading ability; 2 ) introduction about what the text is all about through relevant experiences or situations, and 3) aid sufficient support for the students to "talk, read and think they was purposefully through" the text (Reading for Life, 1997, p.80).

\section{Enhance students' understanding actively}

Teacher needs to promote discussion during pre-reading, during-reading and postreading to ensure that students are actively engaged and enhance their understanding of what they are deciphering. 


\section{Promote readers' active, cognitive and affective process.}

When readers are actively engaged with the texts, and able to construct their own understanding of the authors' intended message, the students are eventually deepening the cognitive and affective process.

\section{Direct involvement with the development of comprehension.}

Teacher can work closely to individual student to monitor their processing of texts and make necessary adjustment of the strategies and the selection of text in the light of the responses. This ongoing supervision will strengthen the needs and skills for better comprehension mastery.

\section{Combination of students' background schemata and new schemata creates meaningful connection.}

Henk (1993) as cited in Biddulph (2002) mentioned that "incoming" information are more likely to create meaningful connections with the existing knowledge structures if relevant schemata are lacking. Pressly (1998) supported the idea of schema activation can "dramatically affect" (p.201) comprehension, attention allocation and better memory of what is read.

\section{Teacher will be aware of the students' diversity of understanding from their reading activity.}

Biddulph (2002) stated that guided reading strategies enables teachers to develop awareness and cater effectively for the diversity created by students through schema activation and extend that knowledge with during reading activities and later with discussion session that follows. However, when students are required to read texts for which they have limited prior knowledge, specific instructional strategies are needed to develop the background knowledge for students' use in the next reading stage activities. Showing of photos, video clips, maps, etc. are example of suggested activities that can be done as initial activity prior to reading.

\section{Guided reading offers a carefully managed "social occurrence" (Biddulph, 2002)}

The teacher put efforts to broaden the students' literacy development by giving appropriate respond to their efforts, continuous support, and guidance as they read (Fountas \& Pinnell, 1996). At this stage, the teacher is not just developed students' ability to understand deeper on specific texts but also polish their metacognitive strategies when engaging with other reading texts.

\section{Guided reading provides many literacy development opportunities.}

Systematic guided reading provides many opportunities through significant individual language and literacy experiences. Some may find it difficult in the beginning, but with consistent guidance and positive authentic interaction from teachers, students may engage more readily and learn more effectively if the discussion takes the form of a genuine conversation (Wiencek \& O'Flahavan, 1994). It helps students to gain more experience and confidence through discovery of new terminologies, projecting their own interpretations of that reading material. 


\section{Active engagement in the guided reading activities is a key to successful learning to read}

The teacher-students collaboration and independence learning experiences will mould students to become competent, persistent readers and writers (Biddulph, 2002).

\section{Guided reading assure meaningful, purposeful, and non-threatening reading experience.}

Reading in a small group permit each student to have opportunities for being an independent reader through self-evaluation of his/her own reading and interaction with other readers through discussion. Teacher guidance will provide direct support and offer challenges through interactive reading activities that activate metacognitive abilities.

\section{Guided reading promotes independence and competence}

Systematic interactive reading activities will ensure students to experience success and enjoyment. The engagement with teacher-students and student-student interaction will establish greater independence and competence.

\section{Guided reading provides comprehension strategies that encourage students to use them} independently during pre-reading, during-reading and post-reading of a reading text.

The fundamental idea to guided reading is the intellectual insight that comprehension strategies will be demonstrated by teacher to be applied by students in pre, during and postreading. Students' engagement in guided reading will train them to learn various strategies across variety genres of texts. Button, Johnson, and Furtyerson (1996) as cited in Biddulph (2002) mentioned that teacher support by providing guidance, demonstrations, and explanations (Dowhower, 1999) will encourage student to use these strategies independently to assist their development as readers.

\section{Guided reading stimulates students to apply all 4-cueing systems}

As reading necessitates a range of metacognitive skills to make sense of the texts, Braunger and Lewis (1998, p.30) as cited in Biddulph (2002) stressed that "most agree that written language relies on four cueing systems the reader uses to interact with text: pragmatic, semantic, syntactic and grapho-phonic. Guided reading encourages students to apply all these four cueing systems as they read to cross-check one source with others. Smith and Elley (1997) highlighted that the use of various cues will help students to achieve a deeper understanding of the authors' intended message thus inspire an inventory of strategies for efficient and independent reading in the future.

\section{Guided reading is an integrative process.}

Freebody and Luke's (1992) thinking model stresses out the standpoint that guided reading is an "integrative" process that merges elements (four cues) of reading whether individually or mutually exclusive. All the cues must not necessarily be performed in tandem for ideal meaning as Luke (1992) mentioned that the cues are systematically introduce to students, not hierarchically, not developmentally but at all stages of literacy development. Freebody and Luke (1992) as cited in Simpson (1996) stated that reading activity applying the four cues concurrently is feasible for skilled students to engage in complex or sophisticated reading materials. 


\section{Conclusion}

Systematic guided reading strategies is a very effective teacher-monitored approach to develop students' reading ability. Even the potential level of effectiveness is unpredictable due to multiple factors (number of students, students' adaptability to the strategies introduced by teachers, range of texts available, etc.), it is great for teachers to use it effectively rather than view the approach only as a fixed activity to work through. Many scholars in reading proposed various strategies to enhance reading abilities however, there is no single approach or strategy that can fit all level of students but feasible with certain modifications. A basic understanding of three main stages of reading strategies is sufficient to associate the methodologies with diverse of approaches. But it is still insufficient to just simply teach comprehension strategies to students. They must be equipped with instructional supports for comprehension strategies, specific knowledge about the field, word recognition, fluency as well as motivation to read (Guthrie et.al, 2009).

\section{Acknowledgement}

This article is based upon work supported by grant awarded by Universiti Utara Malaysia (UUM), Research Grant Code No: 13486.

\section{Corresponding Author}

Nik Intan Baizura binti Ramsa

School of Languages, Civilization and Philosophy, Universiti Utara Malaysia

Email:ms_ramsa@yahoo.co.uk

\section{References}

\section{Journal article}

Abdelhalim, S. M. (2017). Developing EFL Students' Reading Comprehension and Reading Engagement: Effects of a Proposed Instructional Strategy. Theory and Practice in Language Studies, Vol. 7, No. 1, pp. 37-48. DOI:

http://dx.doi.org/10.17507/tpls.0701.05

Alyousef, H. S. (2005). Teaching Reading Comprehension to ESL/EFL Learners. The Reading Matrix, 5(2), 143-154.

Attarzadeh, M. (2011). The Effect of Scaffolding on Reading Comprehension of Various Text Modes on Iranian EFL Learners with Different Proficiency Levels. Scientific International Journal, 8(2), 4-29.

Block, C. C., Whiteley, C. C., Parris, S. R., Reed, K. L., Cleveland, M. D. (2009). Instructional Approaches that Significantly Increase Reading Comprehension. Journal of Educational Psychology, vol.101, no.2 pg.262-281

Block, E. L. (1992). How They Read: Comprehension Monitoring of L1 and L2 Readers. TESOL Quarterly 26(2)

Bulut, A. (2017). Improving $4^{\text {th }}$ grade Primary School Students' Reading Comprehension Skills. Universal Journal of Educational Research 5(1): 23-30 DOI:

10.13189/ujer.2017.050103 http: www.hrpub.org

Chambers, C. S., Almasi, J. F., Carter, J. C., Rintamaa, M., \& Maden, A. (2010). The Impact of a Strategy Based -Intervention on the Comprehension and Strategy Use of Struggling Adolescent Readers. Journal of Educational Psychology, vol.102, no.2 pg.257-280 
Dunkling, L. (2019). Let's Go Back in the Time Machine: An Investigation into the Impact of Strategy- Based Reading Interventions on Year 4 Pupils' Comprehension Skills. The STeP Journal Student Teacher Perspectives Vol 6(1) pages 17-31

Dewitz, P., Jones, J., \& Leahy, S. (2009). Comprehension Strategy Instruction in Core Reading Programs. Reading Research Quarterly, 44(2), 102-126

Dinçay, K. D., Ulum, O. G. (2019). Classroom Implications of Teaching Strategies to Improve Reading. The Reading Matrix: An International Online Journal Volume 19, Number 1, April 2019

Dowhower, S. (1999). Supporting a Strategic Stance in the Classroom: A Comprehension Framework for Helping Teachers Helps Students to be Strategic. The Reading Teacher, vol.52, no.7 pg.678-683

Guthrie, J. T., McRae, A., Coddington, C. S., Klauda, L. S., Wigfield, A., \& Barbosa, P (2009). Impacts of Comprehensive Reading Instruction on Diverse Outcomes oflow- and high-achieving readers. Journal of Learning Disabilities, vol.42, no.3 pg 195-214

McNamara, D. S., O’Reilly, T. P., Best, R. M., \& Ozuru, Y. (2006). Improving adolescent Students' Reading Comprehension with iStart* Journal of Educational Computing Research, 34(2), 147-171

Morales, H. M. (2017). Effects of scaffolded intensive reading on students' reading comprehension performance. Revista Electrónica "Actualidades Investigativas en Educación" Volumen 17 Número 1, Año 2017, ISSN 1409-4703 DOI: http://dx.doi.org/10.15517/aie.v17i1.27204

Pardede, P. (2017). A Review on Reading Theories and its Implication to the Teaching of Reading. https://www.researchgate.ney/publication/312228081conferencepaper -nov2017

Tierney, R. J. (1998). Literacy Assessment Reform: Shifting Beliefs, Principled Possibilities, and Emerging Practices. The Reading Teacher, vol.11, no.5 pg. 374- 390

Topping, K. J., Samuels, J., \& Paul, T. (2007). Does practice make perfect? Independent reading, quantity, quality, and student achievement. Leaning and Instruction, vol.17 pg. 253-264

Richardson, N. (2010) Guided Reading Strategies for Reading Comprehension. Education Masters. http://fisherpub.sjfc.edu/education_ETD_masters/19

\section{Book}

Biddulph, J. (2002). The Guided Reading Approach, Theory \& Research. Learning Media Limited, New Zealand 0478264755PL-9819

Braunger, J., and Lewis, J. (1998). Building a Knowledge Base in Reading. Oregon: Northwest Regional Educational Laboratory's Curriculum and Instruction Services Omaggio, M. A. (1993). Teaching Language in Context. Boston: Heinle and Heinle Reading for Life. (1997) Wellington, New Zealand: Learning Media Limited 